\title{
Correspondence
}

\section{Impacted Microfilaria in the Lens Capsule.}

\section{To the Editorial Committee of the British Journal of Ophthalmology}

SIRS,-I was much interested in the paper by Min Him Tham and I. B. Hall (Brit. F. Ophthal., $197 \mathrm{I}, \mathbf{5 5}, 484$ ), which constitutes a valuable addition to the literature in this field. It is interesting also that, although $M f$. bancrofti are found in large numbers in the blood, it is distinctly unusual for them to be reported in the anterior chamber, in contrast to $M f$. onchocerca volvulus which are never found in the bloodstream but are frequent denizens of the anterior chamber.

I am obliged to the authors for their reference to my paper (Choyce, 1964), but regret that I have been slightly misquoted.

They say:

"In equatorial Africa, it has been reported that there are half a million filarial patients who are blind (Choyce, 1964)".

What I actually said was:

"The World Health Organization has estimated that there are perhaps as many as half a million onchocercal patients who are blind. You will note the wording of this sentence, because some of us believe that additional factors may be involved in the blindness".

These additional factors have received considerable emphasis in the intervening years. Attention has been drawn, for example, to the importance of food deficiencies and intoxications; e.g. Osuntokun (1971) emphasized the frequency of tropical nutritional neuropathy in Nigeria, including a high incidence of optic atrophy and some cases of choroido-retinitis which he attributed to poisoning by cassava. Cassava contains a cyano-genetic glycoside, from which hydrocyanic acid is released on hydrolysis. Other parasitic diseases are now better documented than formerly, together with their effects on the posterior segment, especially toxoplasmosis and loaiasis.

Genetically-determined ophthalmic disorders brought out by in-breeding are also bound to be more frequent in primitive communities (Choyce, 1958).

I think the statement that half a million onchocercal patients are blind still holds good to-day, but how much of the blindness is due to onchocerciasis and how much should be attributed to these other factors mentioned above is a most difficult exercise and I should not care to commit myself at this time.

9 DRAKE ROAD, WESTCLIFF-ON-SEA, ESSEX, SSO 8LR

September 25, 197 I
Yours faithfully, D. P. СHоусе

\section{References}

CHOYCE, D. P. (1958) Trans. roy. Soc. trop. Med. Hyg., 52, 112

(1964) Trans. ophthal. Soc. U.K., 84, $37 \mathrm{I}$

osuntokun, B. o. (1971) Trans. roy. Soc. trop. Med. Hyg., 65, 454 